\title{
SELECTION OF RAW-STARCH DIGESTIVE GLUCOAMYLASE-PRODUCING RHIZOPUS STRAIN
}

\author{
FRANCISCO BENZUELA ELEGADO AND YUSAKU FUJIO* \\ Department of Food Science and Technology, Faculty of Agriculture, \\ Kyushu University, Higashi-ku, Fukuoka 812, Japan
}

(Received April 23, 1993)

\begin{abstract}
Thirty-nine Rhizopus isolates and 9 authentic Rhizopus strains were grown on wheat bran solid culture and assayed for their soluble starch digestive glucoamylase (GA) and raw-starch digestive glucoamylase (GARS). Results showed that the Rhizopus strains tested can be classified into 4 groups based on their GA and GARS production and ratio of GARS to GA. Four Rhizopus isolates and 2 authentic Rhizopus strains produced reasonable amount of GA and GARS activities (GA > 100 units/ml and GARS $>10$ units $/ \mathrm{ml}$ ) in the solid culture extracts, having ratios of GARS to GA activity $>0.10$. The strain with the highest ratio of GARS to GA (F75) was selected for medium optimization. The highest GA- and GARS-producing Rhizopus strain (IFO 4697), Rhizopus F75 and a good glucoamylase-producing Aspergillus niger (K-20) were cultured using the optimum medium and the glucoamylase enzymes produced were further characterized based on saccharification rate on various raw starches and rates of simultaneous saccharification and fermentation in combination with baker's yeast.
\end{abstract}

Glucoamylase [EC 3.2.1.3] was conventionally assorted into two types $(9,10)$, i.e. raw and soluble starch digestive glucoamylase I and soluble starch digestive glucoamylase II. The former can digest both soluble and insoluble raw starch particles but the latter can digest only soluble starch. The raw starch digestive activity (GARS) could be beneficial in the viewpoint of energy saving, because the saccharification of starch can be carried out without gelatinization by cooking (2). This special enzyme characteristic was utilized for possible industrial applications such as the production of ethanol from uncooked starch (6). Among several glucoamylase-producing microorganisms, some strains of the genus Rhizopus and

* Address reprint requests to: Dr. Yusaku Fujio, Department of Food Science and Technology, Faculty of Agriculture, Kyushu University, 6-10-1 Hakozaki, Higashi-ku, Fukuoka 812, Japan. 
Aspergillus were known as good glucoamylase producers and they are being used in industrial glucoamylase production (8). Multiple forms of glucoamylases were found to be secreted by Aspergillus awamori var. kawachi $(3,4)$, Rhizopus sp. (7), and Aspergillus niger (1). Other fungi were found to secrete raw-starch digestive glucoamylase with special characteristics, such as that of thermophilic Rhizomucor pusillus (5). However, it is still not clearly elucidated how much amount of GARS is contained in the total glucoamylase activity or how the GARS to GA ratio affects the raw-starch hydrolyzing power of the glucoamylase enzyme. Here, we screened several Rhizopus strains based on GARS contained in the total glucoamylase activity and assessed the hydrolytic capability on various raw starches and simultaneous saccharification and fermentation (SSF) of raw cassava starch by three selected strains.

\section{MATERIALS AND METHODS}

Microorganisms. A total of 39 Rhizopus strains, isolated from "ragi" by plating and microscopic inspection, and 9 authentic strains of Rhizopus strains (IFO stock cultures) were used in this study. Aspergillus niger K-20, a good glucoamylase producer from our laboratory stock, and a commercial glucoamylase preparation from Rhizopus sp. (Gluczyme GR-2, Amano Pharmaceutical Co., Nagoya, Japan) were also used for reference (Table 1).

Cultivation. Based on Fujio et al. (2), the Rhizopus strains and A. niger reference strain were pre-cultured in potato dextrose agar (PDA) slopes for 10 days. One milliliter of spore of each strain was inoculated into the medium consisting of $20 \mathrm{~g}$ wheat bran, $2 \mathrm{~g}$ corn starch (Wako Pure Chemical Industries, Ltd., Tokyo, Japan) and $20 \mathrm{ml}$ tap water, pre-sterilized at $121^{\circ} \mathrm{C}$ for $15 \mathrm{~min}$ in cotton plugged $500 \mathrm{ml}$ Erlenmeyer flasks. Cultivation was carried out at $30^{\circ} \mathrm{C}$ for 7 days.

Crude enzyme extraction. Two hundred milliliters of deionized water was added into the flask culture, crushed into small parts to hasten enzyme extraction, and placed at $4{ }^{\circ} \mathrm{C}$ for $12 \mathrm{~h}$. It was then filtered through a Toyo No. 2 filter paper, pre-coated with Celite and the filtrate was centrifuged at $10,000 \times g$. Finally, about $180 \mathrm{ml}$ of clear crude enzyme extract was obtained which was subsequently assayed for GA and GARS activities.

GA and GARS activity assay. For GA activity, a reaction mixture consisting of $0.5 \mathrm{ml}$ crude enzyme solution, $2.5 \mathrm{ml}$ of $1 \%$ soluble starch solution, $0.5 \mathrm{ml}$ acetate buffer $(0.3 \mathrm{M}, \mathrm{pH} 4.5)$ and $0.5 \mathrm{ml}$ deionized water was incubated at $40^{\circ} \mathrm{C}$ for $10 \mathrm{~min}$. On the other hand, GARS activity was assayed by reacting $0.5 \mathrm{ml}$ crude enzyme solution (containing GARS activity previously diluted to obtain equal values of 30 units of GA activity) to $2.5 \mathrm{ml}$ of $2 \%(\mathrm{w} / \mathrm{v}$ ) raw corn starch (Wako Pure Chemical Industries, Ltd.) suspension, $0.5 \mathrm{ml}$ of similar acetate buffer, and $0.5 \mathrm{ml}$ deionized water. The reaction mixture, contained in an L-test tube, was incubated with modulate shaking at $40^{\circ} \mathrm{C}$ for $60 \mathrm{~min}$. The increase of glucose liberated was 
estimated enzymatically by Glucose B-Test Kit (glucose oxidase method, Wako Pure Chemical Industries Ltd.). One unit of GA or GARS activity was defined as $1 \mu \mathrm{mol}$ liberated glucose per min-ml crude enzyme solution. The digestive activities on soluble starch and on raw starch were termed as GA and GARS, respectively.

Saccharification and fermentation tests. The saccharification rates of various raw starches by the crude enzyme obtained from the cultures of the Rhizopus strains with the highest GARS and the highest ratio of GARS to GA, and A. niger K-20 as control strain, were determined. The reaction was allowed to occur for $2 \mathrm{~h}$ and samples were assayed for their glucose amount. For the SSF experiment, the initial broth consisted of $30 \mathrm{~g}$ of solid culture of the strain (koji), $5 \mathrm{~g}$ baker's yeast, $100 \mathrm{~g}$ raw cassava starch, $300 \mathrm{ml}$ deionized water and $0.06 \mathrm{~g} \mathrm{~K}_{2} \mathrm{~S}_{2} \mathrm{O}_{5}$ and the $\mathrm{pH}$ was adjusted to $\mathrm{pH} 4.5$. It was placed in $500 \mathrm{ml}$ Erlenmeyer flask, equipped with sulfuric acid trap, and was incubated with slow shaking at $30^{\circ} \mathrm{C}$. The carbon dioxide evolved was monitored by the loss in weight.

\section{RESULTS AND DISCUSSION}

\section{GA and GARS production of Rhizopus}

Table 1 shows GA and GARS activity from all Rhizopus strains, $A$. niger K-20 and a commercial GA preparation used and the ratio of GARS to GA activity. From among them, 9 Rhizopus isolates (G9, F76, F55, F91, F69, F70, F94, Rh3 and Rh4) and 2 reference Rhizopus strains (IFO 4697 and IFO 5441) showed GA activity higher than 100 units. The highest producing strain was IFO 4697 with 125 units of GA activity. On the contrary, $A$. niger K-20 showed the highest GA activity of 154 units under a reaction $\mathrm{pH}$ of 4.5 (although its optimum $\mathrm{pH}$ of reaction is reportedly $\mathrm{pH} 3.5$ ). The higher GARS activity of more than 10 units were given by Rhizopus isolates F75, F76, G9, Rh3 and Rh4 and Rhizopus javanicus IFO 4697, IFO 5318 and IFO 5441. The GARS/GA ratio of more than 0.10 were given by F60, F62, F64, F67, F71, F75, F76, F88, F98, G1, G2, G9, Rh3, Rh4, IFO 4697, IFO 5318 and IFO 5441. Among these, the strain which has a considerable GARS activity and which gave the highest GARS/GA ratio was F75. A. niger K20 gave only 4 units of GARS, hence the GARS/GA ratio was only 0.03 . For Gluczyme GR-2, the GARS/GA ratio was 0.09 , typical of some Rhizopus strains.

\section{Classification of Rhizopus strains}

It may be possible to classify the 49 Rhizopus strains into 4 groups (A, B, C and $D$ in Table 1) based on GA and GARS production on wheat bran medium and the ratio of GARS to GA. Group A strains are good in both GA and GARS production, and can be considered as the best strains for total glucoamylase production. Group B strains are also good in GA production but have lower content of GARS. Group $\mathrm{C}$ strains are the good strains for GARS production although GA production is low, while others (Group D) showed low production for both GA and GARS. The strains with the higher ratio of GARS to GA in 
Table 1. Classification of Rhizopus strains based on their production of GA and GARS on wheat bran medium and the ratio of GARS to GA.

\begin{tabular}{|c|c|c|c|c|c|c|c|c|c|}
\hline Strain & $\underset{\text { (unit } / \mathrm{ml})}{\mathrm{GA}}$ & $\begin{array}{l}\text { GARS } \\
\text { (unit } / \mathrm{ml} \text { ) }\end{array}$ & $\begin{array}{l}\text { GARS/GA } \\
\text { (unit/unit) }\end{array}$ & Group $^{a}$ & Strain & $\underset{\text { (unit } / \mathrm{ml} \text { ) }}{\mathrm{GA}}$ & $\begin{array}{l}\text { GARS } \\
\text { (unit } / \mathrm{ml} \text { ) }\end{array}$ & $\begin{array}{l}\text { GARS/GA } \\
\text { (unit/unit) }\end{array}$ & Group \\
\hline A 11 & 79 & 4 & 0.05 & $\mathrm{D}$ & G1 & 7 & 1 & - & D \\
\hline A19 & 47 & 2 & 0.04 & $\mathrm{D}$ & G2 & 35 & 4 & 0.11 & $\mathrm{D}$ \\
\hline A63 & 61 & $-^{b}$ & - & $\mathrm{D}$ & G4 & 86 & 3 & 0.02 & $\mathrm{D}$ \\
\hline F55 & 100 & 9 & 0.09 & B & G9 & 118 & 14 & 0.12 & A \\
\hline F60 & 45 & 7 & 0.14 & $\mathrm{C}$ & G16 & 81 & 2 & 0.02 & $\mathrm{D}$ \\
\hline F61 & 54 & - & - & D & G17 & 79 & 7 & 0.09 & D \\
\hline F62 & 40 & 5 & 0.13 & $\mathrm{C}$ & G20 & 50 & - & - & D \\
\hline F64 & 41 & 6 & 0.15 & $\mathrm{C}$ & G22 & 89 & 2 & 0.02 & D \\
\hline F67 & 55 & 7 & 0.13 & $\mathrm{C}$ & G24 & 47 & 1 & - & D \\
\hline F68 & 54 & - & - & $\mathrm{D}$ & G25 & 86 & 3 & 0.03 & D \\
\hline F69 & 103 & 5 & 0.05 & B & G82 & 47 & 4 & 0.09 & D \\
\hline F70 & 116 & 5 & 0.04 & B & Rh3 & 119 & 12 & 0.10 & A \\
\hline F71 & 51 & 6 & 0.12 & $\mathrm{C}$ & Rh4 & 102 & 12 & 0.12 & A \\
\hline F73 & 91 & 2 & 0.02 & D & \multicolumn{5}{|c|}{ IFO Rhizopus strains } \\
\hline F75 & 68 & 11 & 0.16 & $\mathrm{C}$ & 4697 & 125 & 15 & 0.12 & A \\
\hline F76 & 122 & 13 & 0.11 & A & 4726 & 76 & 6 & 0.08 & $\mathrm{D}$ \\
\hline F77 & 51 & 1 & - & $\mathrm{D}$ & 4734 & 46 & 5 & 0.11 & $\mathrm{C}$ \\
\hline F79 & 96 & 1 & - & D & 4754 & 98 & 9 & 0.09 & D \\
\hline F81 & 96 & 6 & 0.06 & $\mathrm{D}$ & 4801 & 99 & 9 & 0.10 & $\mathrm{D}$ \\
\hline F86 & 97 & 6 & 0.06 & $\mathrm{D}$ & 5318 & 96 & 13 & 0.13 & $\mathrm{C}$ \\
\hline F87 & 96 & 5 & 0.05 & $\mathrm{D}$ & 5438 & 74 & 5 & 0.07 & D \\
\hline F88 & 42 & 5 & 0.12 & $\mathrm{C}$ & 5441 & 107 & 13 & 0.12 & A \\
\hline F89 & 95 & 7 & 0.07 & $\mathrm{D}$ & 5442 & 97 & 6 & 0.06 & D \\
\hline F91 & 110 & 7 & 0.06 & B & \multicolumn{5}{|c|}{ Aspergillus niger } \\
\hline F94 & 112 & 4 & 0.04 & B & K-20 & 154 & 4 & 0.03 & B \\
\hline F98 & 56 & 9 & 0.16 & $\mathrm{C}$ & GR $-2^{c}$ & $1.6 \times 10^{4}$ & $1.5 \times 10^{3}$ & 0.09 & \\
\hline
\end{tabular}

${ }^{a}$ Group A, GA > 100, GARS > 10, GARS/GA >0.10; Group B, GA >100, GARS $<10$, GARS/GA $<0.10$; Group C, GA $<100$, GARS $>5$, GARS/GA $>0.10$; Group D, GA $<100$, GARS $<10$, GARS/GA $<0.10$.

${ }^{b}$ Activity not detected.

c Commercial glucoamylase preparation (Gluczyme).

groups $\mathrm{A}$ and $\mathrm{C}$ may be improved for both GA and GARS production by medium optimization or genetic manipulation. We considered strain F75, the best strain in group $\mathrm{C}$ and which also has the highest GARS/GA ratio, as the target strain for improvement of GARS production by medium optimization.

\section{Medium optimization for F75 strain}

Addition of organic additives into wheat bran medium in order to try to increase the GARS content of F75 strain was attempted. In the limit of the experiments, the results showed that supplementation with inositol was slightly effective for GARS production, but not for GA production thus increasing the ratio of GARS to GA. Supplementation with 1.0-1.5\% meat extract, $2.0 \%$ yeast extract and from $1.0-3.0 \%$ of peptone slightly increased both GA and GARS production. 
On the basis of these initial results, the cultivation with mixed additives was then tried. The optimum supplements for the wheat bran medium were found to be $0.05 \%$ inositol, $0.25 \%$ peptone, $0.5 \%$ yeast extract and $0.4 \%$ meat extract, producing 92 units of GA activity and 16 units of GARS and increasing GARS/GA ratio to 0.18. Comparing with the control culture, GA and GARS production were improved $28 \%$ and $33 \%$, respectively.

\section{Saccharification of various raw starches}

The results of the hydrolyses of various raw starches by the crude enzyme extracts of three selected strains are shown in Fig. 1. Wheat and cassava starches were seen as the most favored substrate by all strains. Rhizopus strain F75 showed higher hydrolysis rates on all starches compared to the two other test strains which suggests that the higher ratio of GARS to GA or a lesser amount of other amylases in the enzyme extract could be beneficial for raw starch digestion. The low value for GA activity may be seen as advantageous in the viewpoint of lesser probability of inhibition through blocking or competition for substrate with GARS.

\section{SSF experiment}

The results of SSF of raw cassava starch by the "koji"-yeast mixtures of the test strains are shown in Fig. 2. The time course of SSF was initially faster for $R$. javanicus IFO 4697 as it is the best GA and GARS producer. However, after the second day of fermentation and onwards, Rhizopus strain $\mathrm{F} 75$ gave the highest $\mathrm{CO}_{2}$ evolution rate. On the other hand, the poor SSF performance of $A$. niger K-20 may be attributed to the limited capability of its glucoamylase to fully hydrolyze the amylopectin and glycogen component of the raw starch, unlike that of Rhizopus sp. glucoamylase which could hydrolyze $100 \%$ of these components (8).

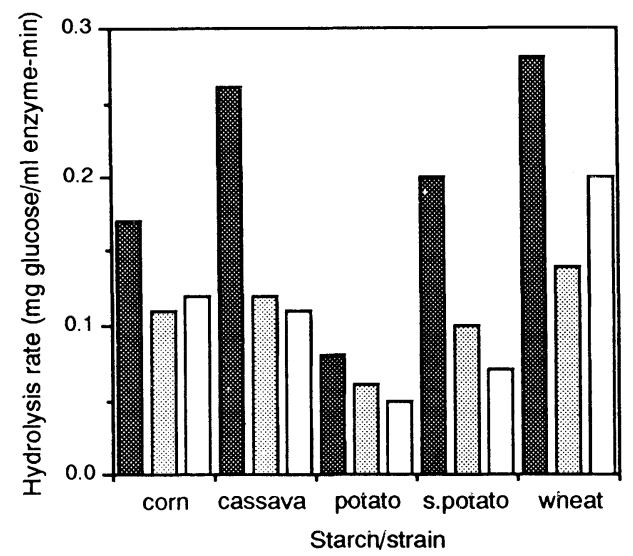

Fig. 1. Hydrolysis rates of various raw starches by selected strains.

, Rhizopus strain F75; [1, Rhizopus javanicus IFO 4697; $\square$, Aspergillus niger K-20. 


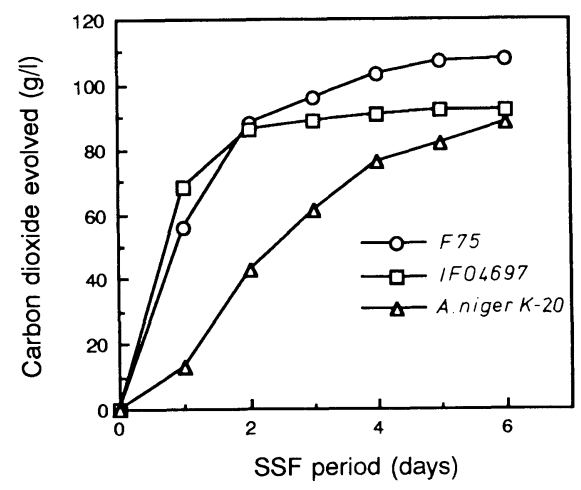

Fig. 2. Time course of the SSF of raw cassava starch by selected strains.

Fermentation parameters: $100 \mathrm{~g}$ raw cassava starch, $30 \mathrm{~g}$ "koji," $5 \mathrm{~g}$ yeast, $0.06 \mathrm{~g}$ $\mathrm{K}_{2} \mathrm{~S}_{2} \mathrm{O}_{5}, 300 \mathrm{ml} \mathrm{d}$. water, $30^{\circ} \mathrm{C}$.

\section{REFERENCES}

1) Boel, E., Hjort, I., Svensson, B., Norris, F., Norris, K. E., and Fiil, N. P., Glucoamylase G1 and G2 from Aspergillus niger are synthesized from two different but closely related mRNAs. EMBO J., 3, 1097 (1984).

2) Fujio, Y., Suyanadona, P., Attasampunna, P., and Ueda, S., Alcoholic fermentation of raw starch by Rhizopus koji without cooking. Biotechnol. Bioeng., 26, 315-319 (1984).

3) Hayashida, S., Selected submerged productions of three types of glucoamylases by a black-koji mold. Agric. Biol. Chem., 39, 2093 (1975).

4) Hayashida, S., Nakahara, K., Kanlayakrit, W., Hara, T., and Teramoto, Y., Characteristics and function of raw-starch-affinity site on Aspergillus awamori var. kawachi glucoamylase I molecule. Agric. Biol. Chem., 53, 143-149 (1989).

5) Kanlayakrit, W., Ishimatsu, K., Nakao, M., and Hayashida, S., Characteristics of raw-starchdigesting glucoamylase from thermophylic Rhizomucor pusillus. J. Ferment. Technol., 65, 379-385 (1987).

6) Matsumoto, N., Fukushi, O., Miyanaga, M., Kakihara, K., Nakajima, E., and Yoshizumi, H., Industrialization of a noncooking system for alcoholic fermentation from grains. Agric. Biol. Chem., 46, 1549-1557 (1982).

7) Takahashi, T., Tsuchida, Y., and Irie, M., Purification and some properties of three forms of glucoamylase from a Rhizopus species. J. Biochem., 84, 1183-1194 (1978).

8) Tsujisaka, Y., Fungal glucoamylase. In Handbook of Amylase and Related Enzymes, Ch. 2, ed. by The Amylase Research Society of Japan, Pergamon Press, Tokyo (1988), p. 117-120.

9) Ueda, S., Studies on the amylolytic system of the black-koji molds. Part II. Raw starch digestibility of the saccharogenic amylase fraction and its interaction with the dextrogenic amylase fraction. Bull. Agric. Biol. Chem. Jpn., 21, 284-290 (1957).

10) Ueda, S., Glucoamylase. In Handbook of Amylase and Related Enzymes, Ch. 2, ed. by The Amylase Research Society of Japan, Pergamon Press, Tokyo (1988), p. 116-117. 